\title{
Greek Warrior Helmet Facies (Wolf-hirschhorn Syndrome)
}

\author{
Biswas $\mathrm{P}^{1}$, Choudhury $\mathrm{R}^{2}$, Gayen $\mathrm{S}^{3}$, Guha $\mathrm{D}^{4}$, Roy $\mathrm{S}^{5}$, Dasgupta $\mathrm{MK}^{6}$
}

\begin{abstract}
Wolf-Hirschhorn syndrome (WHS) is caused by a chromosomal deletion of the band $4 \mathrm{p} 16.3$ with characteristic craniofacial features -'Greek warrior helmet' ${ }^{\prime 5}$ facies (prominent glabella, hypertelorism, broad beaked nose and frontal bossing), high-arched eyebrows, protruding eyes, epicanthal folds, short philtrum, distinct mouth with downturned corners, micrognathia, dysplastic ears, preauricular tags. Till date there are very few case reports of Wolf-Hirschhorn syndrome. Here we report a case that had characteristic dysmorphic facies (Figure1) 'Greek warrior helmet' and was diagnosed as a case of WHS. But presence of Meningo-encephalocele and lissencephaly is rarely reported in literature in association with Wolf-hirschhorn syndrome till date.
\end{abstract}

\section{Introduction}

W olf-Hirschhorn syndrome (WHS) is caused by a chromosomal deletion of the band $4 \mathrm{p} 16.3^{1}$ and was first described in 1961 by the Herbert L. Cooper and Kurt Hirschhorn ${ }^{2}$ and thereafter by Ulrich Wolf, and Hirschhorn and their co-workers in 1965 in the articles in the German scientific magazine 'Humangenetik' ${ }^{3.4}$. Wolf-Hirschhorn syndrome is a congenital malformation syndrome characterized by pre- and postnatal growth deficiency, developmental disability of variable degree, characteristic craniofacial features -'Greek warrior helmet' ${ }^{5}$ facies (prominent glabella, hypertelorism, broad beaked nose and frontal bossing), high-arched eyebrows, protruding eyes, epicanthal folds, short philtrum, distinct mouth with downturned corners,micrognathia, dysplastic ears, preauricular tags), and a seizure disorder. The typical craniofacial phenotype in combination with mental retardation, seizures, congenital heart defects, genital and renal anomalies is indicative of the diagnosis ${ }^{6.7}$. Most of patients with WHS have a de novo deletion, usually on the paternal chromosome ${ }^{8}$. De novo unbalanced translocations have also been described in $1.6 \%$ of WHS patients ${ }^{9}$. The translocation $t$ $(4 ; 8)(p 16 ; p 23)^{10}$ may be the most frequent after $t(11 q ; 22 q)$, which is the most common reciprocal translocation in humans ${ }^{11}$. It can be demonstrated by FISH(Fluorescence in situ hybridization) technique in cytogenetically normal parents of affected offspring ${ }^{12}$. A familial translocation is responsible for only $5-13 \%$ of cases $^{13}$. WHS is mostly maternally inherited with a 2:1 ratio female to males ${ }^{14}$.
'Dr. Prativa Biswas, MBBS, MD, RMO cum Clinical Tutor, Department of Paediatrics, Midnapur Medical College and Hospital, Paschim Midnapur, ${ }^{2}$ Dr. Rupam Choudhury, MBBS, Junior Resident, Department of Tropical Medicine, School of Tropical Medicine, Kolkata, ${ }^{3}$ Dr. Sibnath Gayen, MBBS, MD, Assistant Professor, Department of Paediatrics, R.G. Kar Medical College and Hospital, Kolkata, ${ }^{4}$ Dr, Debashree Guha, MBBS, MD, RMO cum Clinical Tutor, Department of Paediatrics, R.G. Kar Medical College and Hospital, Kolkata, ${ }^{5}$ Dr. Sutirtha Roy, MBBS, Medical Officer, Department of Neonatology, R.G. Kar Medical College And Hospital, Kolkata, ${ }^{6}$ Professor Dr. Malay Kumar Dasgupta, MBBS, MD, Professor, Department of Paediatrics, R.G. Kar Medical College and Hospital, Kolkata.

Department Attributed- Department of Paediatrics, R.G.Kar Medical College, Kolkata.

\section{Address for correspondence:}

Dr. Prativa Biswas

E-mail: prativa1108@gmail.com

\section{How to cite}

Biswas P, Choudhury R, Gayen S, Guha D, Roy S, Dasgupta MK. Greek Warrior Helmet Facies (Wolf-hirschhorn Syndrome). J Nepal Paediatr Soc 2014;34(3):239-243.

doi: http://dx.doi.org/10.3126/jnps.v34i3.10289

This work is licensed under a Creative Commons Attribution 3.0 License.

\section{(c) (i)}

\section{The Case}

Here we report a case of female neonate born of a term gestation to a 24 yrs old second gravida. Baby was low birth weight (2kgs) and presented with dysmorphic facies and respiratory distress along with scalp deformity. 
It was a case of normal delivery and antenatal history was uneventful. However there was history of previous child's death in early neonatal period.

Baby was tachypneic (respiratory rate of $80 / \mathrm{min}$ with bilateral subcostal suction) and needed oxygen, $10 \%$ dextrose as intravenous fluid and kept under radiant warmer on servo-control mode.

On examination baby had characteristic dysmorphic facies- prominent glabella, hypertelorism, broad beaked nose and frontal bossing, high-arched eyebrows, protruding eyes, epicanthal folds, short philtrum, distinct mouth with downturned corners, and micrognathia- 'Greek warrior helmet' (Figure1). Baby had polydactyly and syndactyly (Figure 2) of great toe of left foot and syndactyly (Figure 3 ) of ring finger of right hand. (Figure 4)

On palpation there was scalp defect with coming out of meninges and brain matter through the defectmeningo encephalocoel. (Figure 5). Baby showed generalized hypotonia. Baby developed seizure at 2 hours of age and capillary blood glucose was $86 \mathrm{gms} /$ $\mathrm{dl}$, calcium $9 \mathrm{gms} / \mathrm{dl}$ and seizure was controlled by injection phenobarbitone. Baby developed intractable convulsions which was not controlled with multiple anticonvulsants (phenobarbitone, Phenytoin, Lorazepam, Midazolam) and succumbed to death within nine hours of birth.

Investigations: CT scan of brain (Figure 6) showed evidence of wide $(22 \mathrm{~mm})$ bony gap seen in occipito-parietal region with associated meningoencephalocele along with multiple septate cystic areas within it. There was evidence of multiple air-bubbles seen within the herniated component and also within brain parenchyma of occipital lobe. Cerebral sulci are effaced due to lissencephaly. No significant grey-white differentiation seen with loss of differentiation of different deep grey-matter regions. Apart from frontal horn of left ventricle, rest of ventricular system is not identified. Deformity of facial bone with micrognathia is suggestive from CT scan of brain.

Non-contrast CT scan (NCCT) of thorax (Figure 7) and abdomen (Figure 8) shows ill-defined areas of consolidation with air-bronchogram and associated ground-glass haze, seen to occupy almost whole of both lung fields, sparing anterior aspects of basessuggestive of hyaline membrane disease. Mediastinal vascular structures were normal. No significant abnormalities were seen in abdominal structures from NCCT except hepatomegaly. Echocardiography showed no congenital structural abnormality.

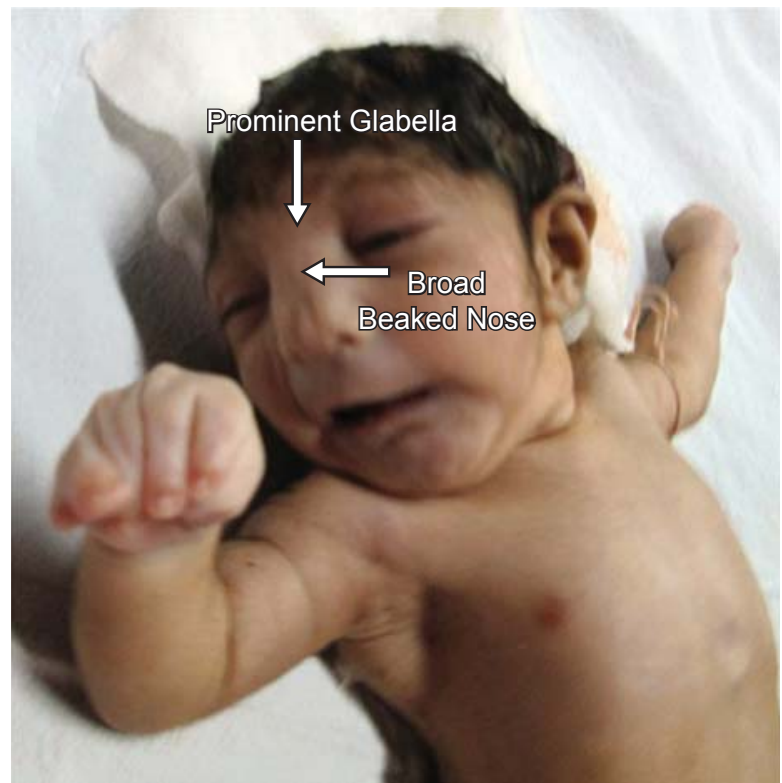

Fig 1: Showing dysmorphic facies

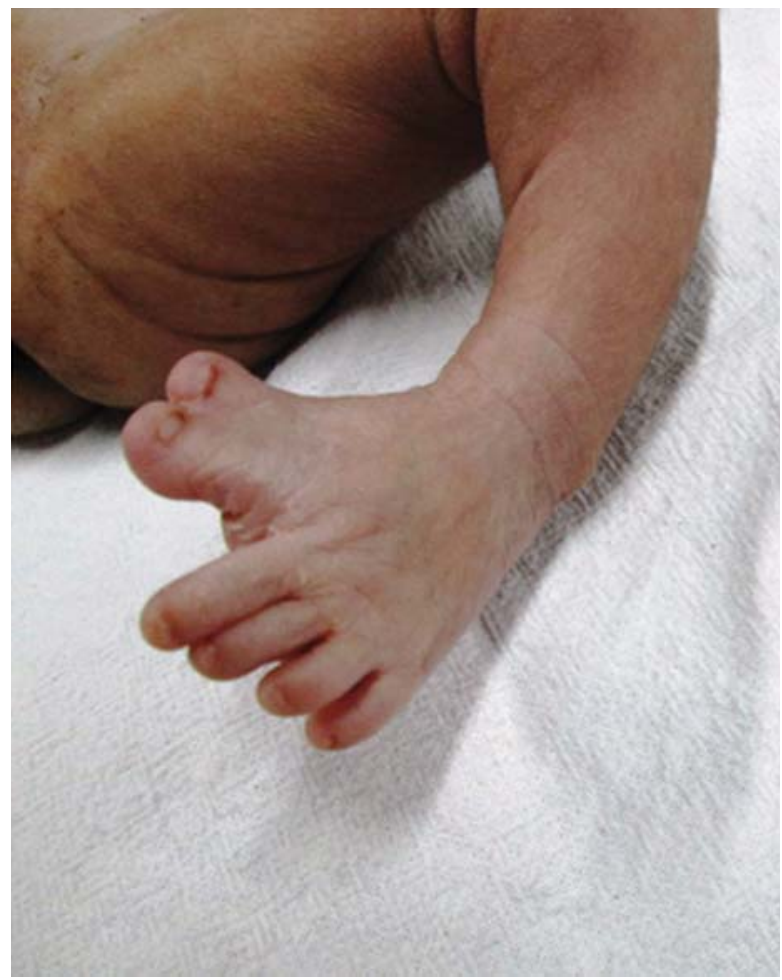

Fig 2: Showing Polydactyly and Syndactyly of Great Toe of Left Foot 


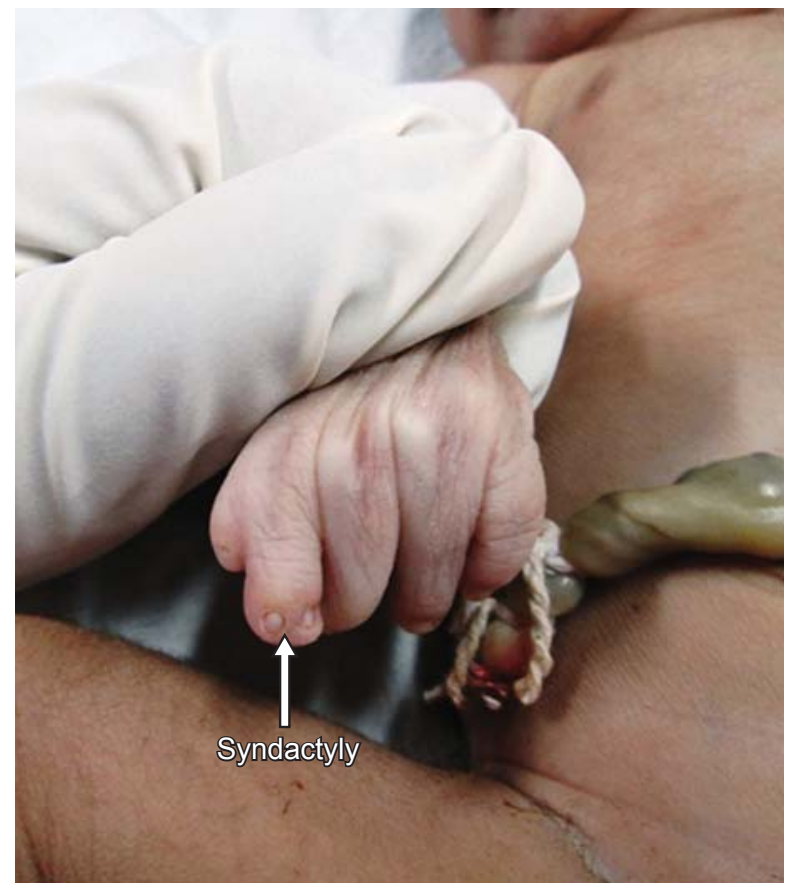

Fig 3: Showing Syndactyly of the Right Hand

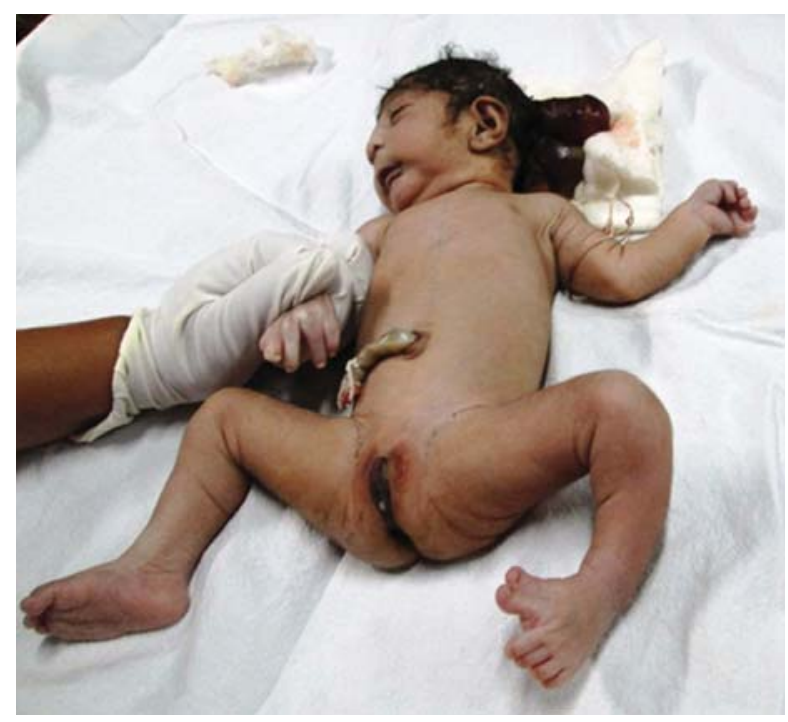

Fig 4: Whole Body Showing Generalised Hypotonia

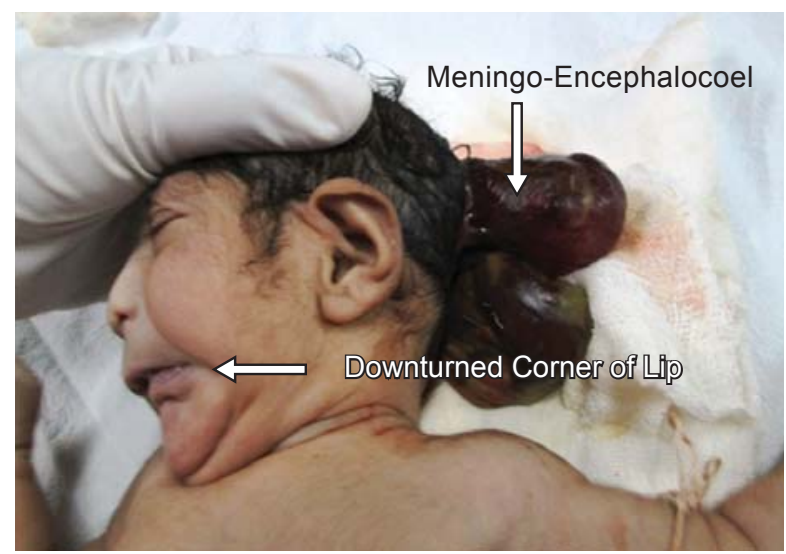

Fig 5: Showing Meningo-Encephalocoel

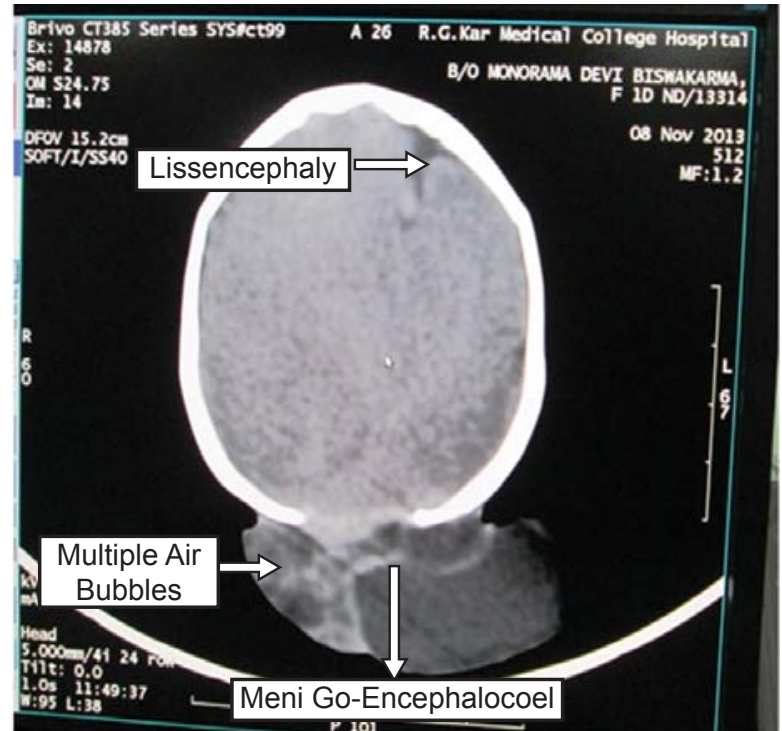

Fig 6: C T Scan Showing Meningo-Encephalocoel

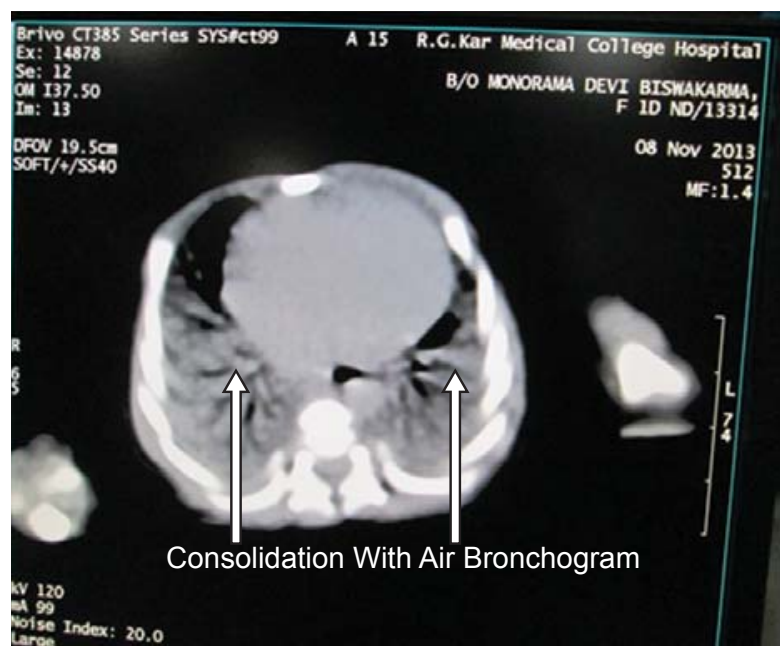

Fig 7: C T Scan Thorax

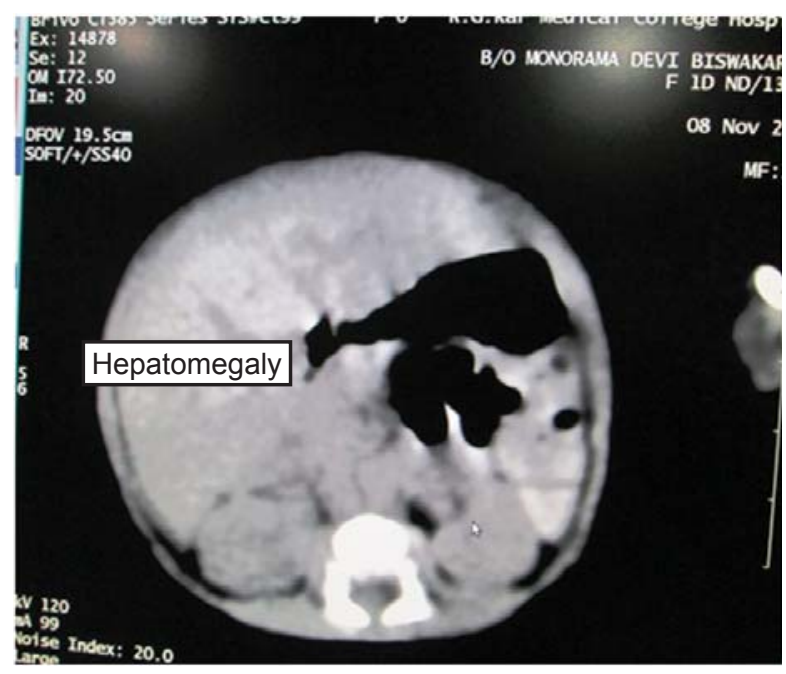

Fig 8: C T Scan Abdomen 


\section{Discussion}

Wolf-hirschhorn syndrome is a rare $4 p$ deletion syndrome with characteristic facial traits, CNS malformations (30\%), low birth weight, short stature, muscular hypotonia, seizures (50-100\%), congenital heart defects, colobomata of iris, genito urinary anomalies (25\%), deafness, abnormalities of dermatoglyphics and skeletal abnormalities (60-70\%) ${ }^{15}$. Battaglia ${ }^{16}$ evaluated 15 patients of which (33.3\%) had heart lesions; (47\%) had orofacial clefts; (87\%) had a seizure disorder.A literature review ${ }^{17}$ of 22 reports of neuroimaging findings in WHS indicated that the most common findings were corpus callosum abnormalities (71\%), focal white matter signal abnormalities (46\%), lateral and third ventricle enlargement (42\%), white matter volume reductions (42\%), and periventricular cysts (29\%). In our case there is presence of low birth weight, dysmorphic facies, syndactyly and polydactyly, generalized hypotonia, seizure, CNS anomaly in the form of meningo-encephalocele with lissencephaly.

Since the first Case report in 1961, about 159 cases have been published to till date ${ }^{18}$. Due to limited facilities for cytogenetic studies in India as well as in other developing countries, confirmatory diagnosis cannot be established in majority of cases. This may be the reason for the less number of published cases.

\section{Conclusion}

In a child with a clinical entity of mental retardation, associated with dysmorphic features and congenital anomalies, cytogenetic studies may help establish a specific diagnosis, which can predict the clinical outcome. There is no treatment available for this rare genetic syndrome but a multidisciplinary team approach is required including rehabilitation, speech communication therapy and genetic counselling. The risk of a parent having another child is unlikely unless the parent is a carrier of the disorder. Thus, parental advice for prenatal diagnosis should also be taken into consideration where facilities allow.

\section{References}

1. Rodriguez $L$, Zollino $M$, Climent $S$, Mansilla $E$, Lopez-Grondona F, Martinez-Fernandez ML, et al. The new Wolf-Hirschhorn syndrome critical region (WHSCR-2): a description of a second case. Am J Med Genet A 2005; 136: 175-8.

2. Cooper H, Hirschhorn K. Apparent deletion of short arms of one chromosome (4 or 5 ) in a child with defects of midline fusion. Mammalian Chrom Nwsl 1961;4:14.

3. Hirschhorn K, Cooper HL, Firschein IL. Deletion of short arms of chromosome 4-5 in a child with defects of midline fusion. Humangenetik 1965;1(5):479-82.

4. Wolf $U$, Reinwein $H$, Porsch $R$, et al. [Deficiency on the short arms of a chromosome No. 4]. Humangenetik 1965;1(5):397-413.

5. Ferrarini A, Selicorni A, Cagnoli G, Zollino M, Lecce $\mathrm{R}$, Chines $\mathrm{C}$, et al. Distinct facial dysmorphism, preand postnatal growth retardation, microcephaly and seizures, mental retardation and hypotonia. Ital J Pediatr 2003; 29: 393-7.

6. Battaglia A, Carey JC, Viskochil DH, Cederholm P, Opitz JM. Wolf-Hirschhorn syndrome (WHS): a history in pictures. Clin Dysmorphol 2000, 9: 25-30.

7. Wieczorek D, Krause M, Majewski F, Albrecht B, Horn D, Riess O, Gillessen-Kaesbach G. Effect of the size of the deletion and clinical manifestation in Wolf-Hirschhorn syndrome: analysis of 13 patients with a de novo deletion. Eur J Hum Genet 2000,8:519-526.

8. Tupler R, Bortotto L, Bühler EM, Alkan M, Malik NJ, Bösch-Al Jadooa N, Memo L, Maraschio P. Paternal origin of the de novo deleted chromosome 4 in Wolf-Hirschhorn syndrome. J Med Genet 1992;42:201-205.

9. Lurie IW, Lazjuk GI, Ussova YI, Presman EB, Gurevich DB. The Wolf-Hirschhorn syndrome. I. Genetics. Clin Genet 1980;17:375-384.

10. Wieczorek D, Krause M, Majewski F, Albrecht B, Meinecke P, Riess O, Gillessen-Kaesbach G. Unexpected high frequency of de novo unbalanced translocations in patients with Wolf-Hirschhorn syndrome. J Med Genet 2000;37:798-804.

11. Giglio S, Calvari V, Gregato G, Gimelli G, Camanini S, Giorda R, Ragusa A, Guerneri S, Selicorni A, Stumm M, Tonnies $H$, Ventura $M$, Zollino $M$, Neri G, Barber J, Wieczorek D, Rocchi M, Zuffardi O. Heterozygous submicroscopic inversions involving olfactory receptor-gene clusters mediate the recurrent t $(4 ; 8)(\mathrm{p} 16 ; \mathrm{p} 23)$ translocation. Am J Hum Genet 2002;71:276-285.

12. Bergemann AD, Cole F, Hirschhorn K. The etiology of Wolf-Hirschhorn syndrome. Trends Genet 2005; 21: 188-95.

13. Centerwall WR, Thompson WP, Irving EA, Fobes CD. Translocation 4p- syndrome. Am J Dis Child 1975;129:366-370. 
14. Nahara K. Himoto $Y$, Yokoyama Y, Kasai R, Hasta A, Kikkawa K, Takahashi Y, Wkita Y, Kimura S, Kimoto $\mathrm{H}$. The critical monosomic segment in $4 \mathrm{p}$ syndrome: a high-resolution banding study on five inherited cases Jpn J Hum Genet 1984;29:403-413.

15. Chen H. Wolf Hirschhorn syndrome, Atlas of Genetic Diagnosis and Counseling, 2006, Pg-10471050.

16. Battaglia A, Carey JC, Cederholm P, Viskochil DH, Brothman AR, Galasso C. Natural history of Wolf-
Hirschhorn syndrome :experience with 15 cases. Pediatrics 1999; 103(4 pt 1): 830-6.

17. Verbrugge, J., Choudhary, A. K., Ladda, R. Tethered cord, corpus callosum abnormalities, and periventricular cysts in Wolf-Hirschhorn syndrome: Report of two cases and review of the literature. Am J Med Genet 149A: 2280-2284, 2009.

18. Priolo M, Ciccone R, Bova I, Campolo G, Lagana C, Zuffardi O. Wolf- Hirschhorn syndrome. Eur J Med Gen 2006;49:279-91. 